\title{
Organizing to Strategize in the Face of Interactions: Preventing Premature Lock-In
}

\author{
Jan W. Rivkin
}

Nicolaj Siggelkow

University of Pennsylvania

Follow this and additional works at: https://repository.upenn.edu/mgmt_papers

Part of the Business Administration, Management, and Operations Commons, Business and Corporate Communications Commons, Business Intelligence Commons, Cognition and Perception Commons, Cognitive Psychology Commons, Interpersonal and Small Group Communication Commons, Management Information Systems Commons, Management Sciences and Quantitative Methods Commons, Organizational Behavior and Theory Commons, Social Psychology Commons, and the Strategic Management Policy Commons

\section{Recommended Citation}

Rivkin, J. W., \& Siggelkow, N. (2006). Organizing to Strategize in the Face of Interactions: Preventing Premature Lock-In. Long Range Planning, 39 (6), 591-614. http://dx.doi.org/10.1016/j.Irp.2006.10.005

This paper is posted at ScholarlyCommons. https://repository.upenn.edu/mgmt_papers/322

For more information, please contact repository@pobox.upenn.edu. 


\title{
Organizing to Strategize in the Face of Interactions: Preventing Premature Lock-In
}

\author{
Abstract \\ Motivated by real examples that run contrary to conventional wisdom, we examine how firms organize \\ themselves to strategize well. Interactions among decisions make strategizing difficult. They raise the \\ spectre that a firm's strategizing efforts will get stuck in a web of conflicting constraints prematurely, \\ before managers explore a wide enough range of possibilities. A key role of organizing is to free \\ strategizing efforts and encourage broad search. At the same time, organizing must ensure that \\ strategizing efforts are stabilized once the firm discovers an effective set of choices. The need to balance \\ search and stability, we argue, is a central challenge of organizing. We explore this challenge with an \\ agent-based simulation of firms that organize to strategize in the face of interactions. The results shed \\ light on our counterintuitive examples. They show why and when firms may benefit from unnecessary \\ overlap between departments; how and when firms can increase firm-wide search by reining in the search \\ efforts of individual managers; and how and when a change in organizational structure - e.g., a shift from \\ decentralization to integration - may reflect an effective sequence of organizing, rather than a reversal of \\ early mistakes. The disparate examples share an underlying logic. The unnecessary overlap, the reining-in \\ of managers, the period of decentralization - all can be seen as organizational mechanisms that help \\ ensure the broad, early search that a firm needs when interactions among strategic decisions raise the \\ danger of locking-in on a strategy prematurely. \\ Disciplines \\ Business Administration, Management, and Operations | Business and Corporate Communications | \\ Business Intelligence | Cognition and Perception | Cognitive Psychology | Interpersonal and Small Group \\ Communication | Management Information Systems | Management Sciences and Quantitative Methods | \\ Organizational Behavior and Theory | Social Psychology | Strategic Management Policy
}




\section{Organizing to Strategize in the Face of Interactions: Preventing Premature Lock-in*}

Jan W. Rivkin
239 Morgan Hall
Harvard Business School
Boston, MA 02163
(617) 495-6690
jrivkin@hbs.edu

Jan W. Rivkin rvard Business School

(617) 495-6690

jrivkin@hbs.edu

\author{
Nicolaj Siggelkow \\ 2211 Steinberg Hall-Dietrich Hall \\ Wharton School \\ Philadelphia, PA 19104 \\ (215) 573-7137 \\ siggelkow@wharton.upenn.edu
}

\footnotetext{
* Special thanks to Andrew Pettigrew and Annie Pye for helpful comments and to Howard Brenner for computer programming assistance. We are grateful to the Mack Center for Technological Innovation and the Division of Research of Harvard Business School for generous funding. Errors remain our own.
} 


\title{
Organizing to Strategize in the Face of Interactions: Preventing Premature Lock-in
}

\begin{abstract}
Motivated by real examples that run contrary to conventional wisdom, we examine how firms organize themselves to strategize well. Interactions among decisions make strategizing difficult. They raise the specter that a firm's strategizing efforts will get stuck in a web of conflicting constraints prematurely, before managers explore a wide enough range of possibilities. A key role of organizing is to free strategizing efforts and encourage broad search. At the same time, organizing must ensure that strategizing efforts stabilize once the firm discovers an effective set of choices. The need to balance search and stability, we argue, is a central challenge of organizing. We explore this challenge with an agent-based simulation of firms that organize to strategize in the face of interactions. The results shed light on our contrary-to-wisdom examples. They show why firms may benefit from unnecessary overlap between departments; how firms can increase firm-wide search by reining in the search efforts of individual managers; and how a change in organizational structure - e.g., a shift from decentralization to integration - may reflect not a reversal of early mistakes but an effective sequence of organizing. The disparate examples share an underlying logic. The unnecessary overlap, the reining-in of managers, the period of decentralization - all can be seen as organizational mechanisms to ensure the broad, early search that a firm needs in order to cope with interactions among decisions.
\end{abstract}




\section{Introduction}

Despite five decades of research on organizing, real organizations continue to surprise us. Consider a few examples.

- Conventional wisdom holds that good organizational structures are as modular as possible: integrally related decisions are grouped under the purview of a single management team, and managerial overlap is avoided across departments that do not affect one another. Yet in its vehicle development efforts, Toyota intentionally leaves “unnecessary” overlap across departments. As we describe below, the company does not modularize sets of decisions that, in concept, are decomposable, and it seems to benefit as a result.

- Conventional wisdom argues that to catalyze innovation in a firm, senior managers should liberate low-level decision makers and allow them to explore a wide range of alternatives within their separate domains. Yet in an American industrial computing company discussed below, senior executives prompted an outburst of innovation by reining in the exploration conducted by subordinates.

- It is generally held that when top managers restructure their organization, it is to rectify past mistakes, often large and serious ones. In its e-commerce efforts, for instance, discount broker Schwab started with an independent subsidiary, but it soon reintegrated its online and conventional operations - seemingly reversing an earlier organizational error. We will argue below that such sequencing may reflect not a mistake, but an effective way to reach good sets of strategic choices in a novel environment.

These examples suggest that much of what conventional wisdom holds to be true about organizing is sometimes not. Students of organizational design have long recognized the paucity of universal truths in their field. In the 1960s, mounting evidence that little is always true about organizing led researchers to adopt a contingency outlook: prescriptions for organizing may be valid, but each prescription holds true 
only for a subset of the possible environmental conditions. ${ }^{1}$ This begs the question, what are the relevant environmental conditions that define the contingencies? And precisely how do environmental conditions lead to different prescriptions for organizing?

To contribute to tackling two such ambitious questions, we bring two perspectives to bear. First, we focus on one particular role played by organizing. A key goal of organizing is to enable a company to strategize well. We conceive of a firm's management team as facing a set of decisions about how to procure, sell, deliver, service, hire, design, finance, and so forth. For the team, strategizing is the search for a combination of choices that, together, generates strong performance. Organizing is the allocation of rights over the choices to members of the team as well as the coordination of choices through incentives, communication, and hierarchy. Organizing matters greatly in our view because it shapes how a firm strategizes - how it searches for a set of choices and, therefore, what set it eventually adopts. Schwab’s early decision to organize e-commerce as a separate subsidiary, for example, affected how it marketed, priced, executed, and serviced online trades. This view of the relationship between organizing and strategizing is consistent with past research. Prior work has highlighted how organizational structure might affect a firm’s search for a strategy by molding resource allocation and strategic planning processes, by altering how managers perceive opportunity, and by boosting the supply of new managers who pursue new businesses, for instance., 3

The second perspective we bring to bear is a point of view on what makes strategizing difficult. We focus especially on interactions among decisions as a source of challenge. Strategy scholars have long emphasized that the decisions managers face are highly interdependent. ${ }^{4}$ In its early online operations, for example, Schwab’s decision not to offer the very lowest price for an online trade was related to its choice to deploy its valuable brand online: the brand name made it viable to charge a premium over noname e-brokers, and setting the lowest price may have sullied the brand offline. Interactions are not only pervasive but, we argue, they have a profound impact on the difficulty of strategizing. Searching for an effective set of choices is relatively easy when decisions are independent and can be resolved one by one. Strategizing is harder when decisions depend on one another. Tradeoffs then arise across choices, and the 
danger looms that an incremental approach will leave a firm with an internally consistent but not-veryeffective set of decisions. Such a set of decisions would be a local optimum, but it might be far from the global optimum.

Moreover, interactions make organizing - the allocation and coordination of decisions - relevant for strategizing. If the decisions facing a firm were independent, the allocation of them to decision makers would not affect their resolution, and coordination would be unnecessary. One could even assign each choice to a separate decision maker and give everyone complete autonomy over his or her choice. With pervasive interactions, in contrast, organizing can have a deep influence on how strategizing, the search for choices, unfolds and what set of choices a firm eventually adopts. To the first question we posed above - what are the relevant environmental conditions that define contingencies? - we would offer a partial answer: interactions among decisions are one important source of contingency. That is, the right way to organize depends in part on the presence of interactions among a firm's strategic decisions. This echoes prior contingency literature, which focuses on the complexity of a firm's task environment as a key contingency. ${ }^{5}$

The second question posed above - precisely how do environmental conditions lead to different prescriptions for organizing? - is harder to address. To tackle it, we first narrow it, focusing on how degrees of interaction affect prescriptions for organizing. We then use the counterintuitive examples above, involving Toyota, the industrial computing firm, and Schwab, and we couple them with an agentbased simulation model of organizing and strategizing. The model identifies conditions, related to interactions, in which the seemingly odd phenomena of the examples arise. Together, the examples and the model provide some general insight about how a firm should organize to strategize well in the face of interactions. The examples appear quite different, but they have an underlying similarity. In all three cases, the challenge before the management team is to organize in such a way that strategizing efforts explore a considerable variety of configurations of interdependent choices before locking in on one particular configuration. “Unnecessary” overlap between departments in Toyota, restrictions on low-level exploration in the industrial computing firm, and sequenced organizational structures at Schwab may 
serve this purpose. They might prevent a team from locking into a poor set of choices prematurely. Firms that organize to strategize well, we find, manage to avoid premature lock-in. However, they also have the discipline to cease exploration once they have discovered an effective set of choices. In ways we describe below, they balance search and stability.

Our plan of attack is as follows. Section 2 lays out a model of organizing to strategize that is simple, yet is general enough to encompass all three examples. Sections 3, 4, and 5 examine the examples, each with corresponding results from the simulation. Section 6 draws the examples together and offers reflections that span the examples and go beyond them.

\section{A model of organizational search and organizational design}

Techniques and imagery from recent studies of complex adaptive systems can be deployed to visualize how interactions influence both strategizing and organizing. The essential task of a firm's management team, in our conception, is to resolve a host of decisions - decisions that, together, make up the firm's strategy. For instance, managers must decide whether or not to broaden the firm's product line, to increase the advertising budget, to invest more heavily in research and development, to invest in customer relationship management software, etc. The management team can be visualized, then, as operating on a high-dimensional landscape. Each horizontal dimension of the landscape represents one of the decisions, and the vertical dimension records the performance that results from each possible configuration of choices. ${ }^{6}$ Management's problem in strategizing is to find a good combination of choices - to discover a high point on the landscape. Because managers are bounded in their rationality, ${ }^{7}$ the search process involves exploratory, groping behavior - not simply a consideration of all alternatives followed by a leap to the global peak. A common response to the cognitive limits of individual managers is to distribute authority and responsibility for discrete decisions across a number of managers. The allocation of interdependent decisions to independent managers, accompanied by coordinating devices such as incentives, communication, and hierarchy, is at the heart of organizing. 
When a firm's decisions do not interact with each other, in the sense that each decision's contribution to performance does not depend on others, the performance landscape is smooth and single-peaked. Figure 1 shows a highly simplified example of this situation, with just two decisions determining firm performance. The decisions do not interact: the marginal impact of decision 1 on performance does not depend on decision 2, and vice versa (or equivalently, the shape of a cross-section with respect to decision 1 is identical for all levels of decision 2, and vice versa). In such a situation, starting from any combination of choices, one can move to the global optimum by a series of performance-improving changes to individual decisions. Incremental improvement will eventually yield the very best combination of choices, so strategizing is trivial. Moreover, a firm's organizational structure has little bearing on this outcome since, regardless of the allocation of choices, each subset of the firm can safely operate as its own fiefdom. A manager in charge of decision 1 and a manager in charge of decision 2, each maximizing his or her independent contributions, will arrive atop the global peak, even without coordination.

\section{$<$ INSERT FIGURE 1 ABOUT HERE $>$}

If one introduces interactions, however, the performance landscape becomes rugged. Local peaks combinations of choices that provide no opportunity for improvement by means of incremental change proliferate. Figure 2 shows a simple example of such a situation, with each decision's impact on performance now dependent on the choice made with respect to the other decision. Strategizing becomes challenging as the specter arises that a firm may get stranded on a low local peak, unable to find better options despite poor performance. Also, efforts to organize now affect how well the firm copes with the challenge of strategizing. A decision made by one manager may now alter the performance consequences of another manager's choices. If the firm is organized so that low-level managers are left to their own devices, those managers may engage in rounds of mutually destructive improvement efforts, each moving uphill on the portion of the landscape that he or she controls but sinking the portion that others manage. And if those managers are coordinated by a vertical hierarchy, the managers may filter information in order to promote parochial interests, thereby damaging the firm as a whole. In the face of interactions, managers must think carefully about how to organize to strategize. 


\section{$<$ INSERT FIGURE 2 ABOUT HERE $>$}

We embed the ideas behind this imagery in an agent-based simulation model, a model in which firms with different approaches to organizing attempt to strategize. Computer simulations have long been used in management science to create "laboratories" in which researchers can conduct rigorous virtual experiments on modeled organizations. ${ }^{8}$ In agent-based simulations, which have gained popularity recently, researchers model individual agents - in our case, managers - rather than the system as a whole. We confront modeled managers with certain stochastically-generated environments, give them heuristics for reacting to the environment, allow them to interact with one another in a series of periods, and record the resulting behavior over time. By altering the types of environments that managers face and the ways that managers are organized, and by repeating the experiments hundreds of times for each type of environment, we can isolate how well different organizations cope with various types of environment. Let us describe (1) how we model the environment and (2) how we model managers and organizations.

\subsection{Environments with interactions}

The environment we model requires the management team of each firm to resolve $\mathrm{N}$ binary decisions (i.e., yes/no choices). For instance, $a_{1}$ may represent the decision to increase the advertising budget $\left(a_{1}=\right.$ 1 ) or not $\left(a_{1}=0\right)$ while $a_{2}$ may represent the decision to increase product breadth $\left(a_{2}=1\right)$ or not $\left(a_{2}=0\right)$. In total, thus, the firm has $2^{N}$ possible configurations of choices $\mathbf{a}=\left(a_{1}, a_{2}, \ldots a_{N}\right)$, each represented by an $\mathrm{N}$-digit string of zeroes and ones. Using an approach described below, the computer generates a payoff, $\mathrm{V}(\mathbf{a})$, for every configuration of choices. The mapping of all possible choice configurations onto payoffs creates the performance landscape on which a firm is operating. A performance landscape consists of $\mathrm{N}$ "horizontal” dimensions, representing the $\mathrm{N}$ choices a firm has to make, and one "vertical” dimension, which records payoffs.

The payoffs V(a) are generated in a stochastic but well-controlled manner. In particular, each decision $a_{i}$ is assumed to make a contribution to overall performance. The contribution of decision $a_{i}, c_{i}\left(a_{i}\right.$, $\mathbf{a}_{\mathbf{- i}}$ ), depends on how the choice itself is resolved (e.g., whether the advertising budget was increased or 
not) and on how other decisions were resolved that interact with decision $\mathrm{a}_{\mathrm{i}}$ (e.g., whether the product line was extended or not). Formally, an influence matrix $\mathrm{M}$ tracks the interactions among the decisions. $\mathrm{M}$ is an $\mathrm{N}^{*} \mathrm{~N}$ matrix which has an entry in row $i$, column $j$, if column decision $j$ affects row decision $i$. For instance, Panel A of Figure 3 shows an example of a fully interdependent influence matrix with $\mathrm{N}=8$ in which each decision affects each other decision, while Panel B of Figure 3 shows a modular influence matrix in which decisions 1-4 interact richly, decision 5-8 interact richly, but no interactions exist across these two sets of decisions.

\section{< INSERT FIGURE 3 ABOUT HERE >}

Lastly, for each landscape, the particular values of all possible contributions are determined by drawing randomly from a uniform distribution over the unit interval, i.e., $\mathrm{c}_{\mathrm{i}}\left(\mathrm{a}_{\mathrm{i}}, \mathbf{a}_{-\mathrm{i}}\right) \sim \mathrm{u}[0,1]$. The value of a given set of choices $\mathbf{a}$ is then given by the average of the $\mathrm{N}$ contributions:

$$
\mathrm{V}(\mathbf{a})=\left[\mathrm{c}_{1}\left(\mathrm{a}_{1}, \mathbf{a}_{-1}\right)+\mathrm{C}_{2}\left(\mathrm{a}_{2}, \mathbf{a}_{-2}\right)+\ldots+\mathrm{c}_{\mathrm{N}}\left(\mathrm{a}_{\mathrm{N}}, \mathrm{a}_{-\mathrm{N}}\right)\right] / \mathrm{N}
$$

\subsection{Organizations and managers}

To study the effects of different organizational structures, we place firms with different structures onto the same randomly chosen starting point on a performance landscape and let managers within these firms try to find high locations on this landscape over a number of periods (up to 200). Each period, we record the performance of each firm, measuring the firm's value that period, $V(\mathbf{a})$, as a percentage of the value associated with the best possible combination of decisions on the landscape. We then generate a new performance landscape with the same interaction pattern (but with newly drawn contribution values) and let firms again search for high locations. We repeat this procedure 1,000 times to guarantee that performance differences we might detect are driven not by the stochastic elements of the model but by the inherent properties of the different organizational structures. 
To illustrate the phenomena outlined in the Introduction, we focus on three organizational features: the task allocation; the degree of exploration engaged in by department-level managers; and the presence or absence of a hierarchical structure.

Task allocation. The $\mathrm{N}$ decisions of the firm can be allocated in various ways to different decision makers. In our model, we focus on firms with either one or two departments. A string of a's and b’s denotes the allocation of the $\mathrm{N}$ decisions to the two departments. For instance, the task allocation aaaaaaaa would denote an integrated firm that has assigned all eight decisions to one department, while aaaabbbb would denote a firm that has assigned the first four decisions to one department and the other four decisions to the other department.

Degree of exploration by department-level managers. In each period, each department manager considers a number of randomly chosen, local alternatives, ALT, to the current status quo choices. (Local alternatives are alternatives that differ in one individual choice from the current set of choices.) Thus, ALT measures the degree of exploration that department-level managers engage in. For instance, with task allocation aaaabbbb, current choices 00000000, and ALT $=2$, the first manager might consider 1000 and 0010, while the second manager might consider 0100 and 1000. In particular, each manager evaluates the contributions of the decisions that are under his or her control. To continue the example, the first manager, controlling the first four decisions, would compute for each alternative under consideration:

$$
\left.\mathrm{V}_{1}(\mathbf{a})=\left[\mathrm{c}_{1}\left(\mathrm{a}_{1}, \mathbf{a}_{-1}\right)+\mathrm{C}_{2}\left(\mathrm{a}_{2}, \mathbf{a}_{-2}\right)+\mathrm{C}_{3}\left(\mathrm{a}_{3}, \mathbf{a}_{-3}\right)+\mathrm{c}_{4}\left(\mathrm{a}_{4}, \mathbf{a}_{-4}\right)\right)\right] / 4
$$

Decentralized or hierarchical structure. Once the managers have evaluated their ALT alternatives, the firm implements changes, or retains the status quo. In the decentralized structure, each department manager implements the alternative with the highest value for the department or retains the status quo if no alternative yields higher departmental performance. This new choice configuration serves then as the starting point for search in the next period. 
In the hierarchical structure, each manager sends his or her two most preferred alternatives (which may include the status quo) to a “CEO.” The CEO evaluates all possible combinations of alternatives and status quo choices for the two departments and implements the combination that yields highest firm performance. Again, the new choice configuration serves as the starting point for search in the next period. (See Figure 4 for a summary of the two organizational structures.)

$<$ INSERT FIGURE 4 ABOUT HERE $>$

In the following sections, we will present a number of intriguing results generated with this simulation set-up that shed light on the experiences of Schwab (Section 3), Toyota (Section 4), and the industrial computing firm (Section 5) that we sketched in the Introduction. Due to space constraints, we often will not be able to describe all results in full detail or show various robustness tests of the results. The interested reader will find more detail in the papers cited in the references. ${ }^{9}$

\section{The benefit of changing organizational structures}

In 1995, in its attempt to respond to the successful arrival of internet-only brokerage firms, Charles Schwab created a free-standing electronic brokerage unit called e.schwab. The unit was given free reign, moved to a separate building, and held responsible for its own profit and losses. ${ }^{10}$ Illustrating nicely the effect that organizing has on strategizing, the new unit responded with an array of new practices, including new internal software that allowed for a purely electronic customer relationship, a flat pricing scheme rather than the sliding scale of commissions that Schwab used in its traditional brokerage business, and a limited level of services offered to customers. While e.schwab was successful, a number of problems arose. In particular, customers were confused and irritated by the different prices and service levels offered under the same Schwab brand name, and the separate computer systems at e.schwab and Schwab made it difficult for customer representatives to gain access to full customer information. ${ }^{11}$ In 1998, Charles Schwab decided to reintegrate e.schwab. This included eliminating the separate P\&L, renaming e.schwab as Schwab.com, creating flat commissions for all trades, and allowing all customers 
full access to Schwab’s customer services. In sum, the eventual firm became a mix of the e.schwab experiment and the traditional Schwab brokerage.

One reading of this experience is that Schwab did not correctly anticipate the eventual difficulties that arose from creating a spin-off and this forced it to reintegrate e.schwab at a later point. While this might certainly be true, the approach of first decentralizing and later reintegrating turns out to be, as our simulation model shows, a powerful approach for a firm that faces interdependent decisions and needs to reconfigure its set of choices significantly.

To model the effects of different ways of organizing (integration, decentralization, and reintegration), we consider three firms that each faces eight decisions $(\mathrm{N}=8)$. A fully integrated firm assigns all decisions to “one department” (aaaaaaaa). A decentralized firm assigns decisions to two departments and lets each department implement those alternatives it finds profitable (aaaabbbb). A reintegrating firm operates as a decentralized firm (aaaabbbb) for 50 periods, then adopts the integrated task allocation (aaaaaaa). (The results are not sensitive to the choice of 50 periods.) For the simulation presented here, we assume that firms operate on fully interdependent performance landscapes, where each decision affects all others. All three firms are placed on the same, randomly chosen starting point, and each firm's performance is recorded over 200 periods. Figure 5 charts the average performance trajectories of these three firms over 1,000 landscapes.

\section{< INSERT FIGURE 5 ABOUT HERE>}

Figure 5 reveals three patterns. First, in the short run, the integrated firm has a performance advantage over the decentralized firm. Due to the pervasive interactions across the two divisions, each department in a decentralized firm is likely to engage in actions that are beneficial for itself but hurts the firm overall and undermines the improvement efforts of the other department. Such actions slow down the overall performance improvement of the firm as compared to an integrated firm, which rejects changes that could hurt the performance of the whole firm even temporarily.

Second, the decentralized firm outperforms the integrated firm in the long run. In the presence of many interactions, the typical performance landscape becomes very rugged, with many "local peaks” on 
which firms can get stuck. As a result, broad search is valuable. The decentralized firm, with each department free to implement changes that benefit it alone, tends to engage in much broader search than does an integrated firm, which implements only those alternatives that improve performance for the entire firm. Consequently, the decentralized firm fares better than the integrated firm in the long run.

Third, and most striking, the reintegrating firm outperforms either pure structure. To understand this result — and more broadly to understand the general effect of organizing on strategizing — the concept of an organizational "sticking point" is helpful. ${ }^{12}$ Organizational sticking points are configurations of choices from which a firm will not move. Organizational sticking points are, thus, the eventual outcomes of many periods of strategizing, i.e., of searching for high-performing choice configurations. Sticking points have two origins. First, a sticking point can arise when boundedly rational actors have exhausted their knowledge about possible alternatives that they would find more attractive than the status quo. This type of sticking point is very much akin to the notion of a "competency trap."13 Second, a sticking point can arise when no alternative can be found that is acceptable to all those in the organization who must consent to the implementation of the alternative.

Organizational structure has a profound effect on organizational sticking points. For the integrated structure discussed above, a configuration a is a sticking point if no other configuration a' can be found that differs from a in one element and that has higher performance than a. In contrast, for the decentralized structure, configuration a is a sticking point only if neither department manager finds a profitable deviation for his or her department. Thus, different organizational structures lead strategizing efforts to terminate at different sticking points. Moreover, different structures lead to different numbers of sticking points. Decentralized firms are less likely to become stuck; they move if either department manager can spot a parochial improvement. For this reason, decentralized firms tend to search rugged landscapes much more broadly than integrated firms. On the other hand, the decentralized firm suffers from two drawbacks. First, it may wander forever, with department managers adopting sequences of changes that undermine each other. In contrast, the integrated firm always stabilizes around some sticking point - albeit sometimes a mediocre configuration. Second, the decentralized firm may become stuck at a 
point where an incremental change that is attractive for the firm is left unexploited, simply because the change is not parochially appealing to the department that must implement it. The integrated firm, in contrast, never leaves incremental improvements untapped in the long run.

The reintegrating firm couples the broad search of the decentralized firm with the stability and exploitative power of the integrated firm. In its early days, when it resembles a decentralized firm, the reintegrator migrates to a promising area of the landscape. After it changes to become integrated, the reintegrator scales and eventually becomes stuck on a high spot within that area. The early, broad search provided by the decentralized structure puts the firm in a favorable position for further search once the firm reintegrates.

In these results, we see the first instance of a pattern that will recur: organizing (or a change in organizing) can help a firm by preventing its strategizing efforts from terminating too early, i.e., by shaking it off low-performing sticking points.

Our finding - that sequenced organizing improves strategizing - does not hold up under all circumstances. We would emphasize two limitations. First, the finding depends crucially on the presence of interactions. Without them, there is little need for the broad search that the decentralized structure provides. Figure 6 repeats the simulation of Figure 5 but with no interactions among choices. The decentralized firm now has a short-term advantage over the integrated firm because its structure benefits from parallel processing of alternatives in each department. In the long run, all three structures end up on the same global peak of the landscape. Thus, in this case, sequencing from a decentralized to an integrated structure does not help the firm at all.

\section{< INSERT FIGURE 6 ABOUT HERE $>$}

The second limitation concerns the starting point of a firm. For a firm that needs to adjust its activity configuration only slightly, the broad exploration generated by a period of decentralization may lead the firm too far astray. In such cases, an integrated structure can perform better than reintegration. Suppose in our simulation that a firm begins its search D changes away from the best possible activity configuration, the global peak. A firm with a low level of D needs only minor change in its activities to perform its best, 
while a firm with a high level requires radical change. Figure 7 compares the performances in period 200 of integrated and reintegrated firms that start the same distance from the global peak, as a function of that distance. When the firms require only modest adjustment (low D), integration outperforms reintegration (and, though not shown, the decentralized structure as well). It is only at higher D that a period of broad search is beneficial.

\section{< INSERT FIGURE 7 ABOUT HERE >}

This finding sheds light on an observation in the financial services industry: some very successful firms did not follow a path of decentralization followed by reintegration. For instance, Vanguard, one of the world's largest and most successful mutual fund providers, never created an e-commerce division, but adopted Internet technology within its integrated structure from the outset. The contrast between Vanguard and Schwab reflects, we believe, a difference in their starting positions. Vanguard had long had a direct distribution system and mail-based customer information activities. Thus, the company found that the Internet could be plugged into its existing strategy quite naturally. The Internet required it to make relatively modest adjustments. Schwab, in contrast, faced change on many dimensions. It needed the broad search that a decentralized structure provides.

This example highlights a general point. In the literature on technological innovation, technological changes have traditionally been classified as either competence-destroying or competence-enhancing. ${ }^{14}$ We would argue that the character of a technological change is not an inherent property of the change, but depends on a firm's current set of choices. Imagine two firms whose past strategizing efforts have led them to different sticking points. A technological change now raises a new global peak distant from one firm and close to the other. The change is competence-destroying for the first firm, requiring change in many activities, even while it is competence-enhancing for the other, requiring only modest adjustments. Moreover, though the firms experience the same environmental change, they need very different organizational responses: the first firm needs an organizational structure that encourages broad exploration, while the second firm does not. The difference arises because past strategizing efforts left the firms on different sticking points. Past strategizing thus influences the appropriate way to organize. 
In this section, we have focused on one particular sequence of structures, from decentralization to integration, and we have argued that early exploration under decentralization can free a firm from low sticking points. This argument can be broadened. In related work, we have explored organizational structures beyond the integrated and decentralized structures considered here. Each is associated with a different set of sticking points when interactions exist. ${ }^{15}$ After a number of periods of search under any one structure, a firm gravitates towards a stable set of activities. A change to a different organizational structure can dislodge a firm from this stable set, rejuvenating search and leading the firm to a better activity configuration. ${ }^{16}$ A shift in structure does not necessarily imply that the old structure was bad and that the new structure is inherently better; as Figure 5 showed, the new structure, had it been adopted from the beginning, would have led to lower performance on average. The benefit arises from adopting a structure with different sticking points, not from adopting a "better" structure. When choices interact, changes in organizing can spark productive strategizing. This is true even in a stable environment. The academic literature on organizations tends to assume that environmental changes come before, and drive, changes in organizing. Here, we see reasons that top managers might reorganize in a perfectly stable environment, just to "shake things up."

For practicing managers, our results have two key implications. First, if a firm can afford a period of broad search and needs to reconfigure its choices substantially, the firm can benefit by first adopting an organizational structure with parochially-minded sub-divisions, then shifting to a structure that reins in sub-divisions and makes them accountable for their firm-wide impact. Second, when a firm’s performance stagnates - a sign that it may have reached an organizational sticking point - a change in organizing may help the management team dislodge itself from its current set of choices and restart its strategizing efforts, heading towards higher regions of its performance landscape.

\section{Not modularizing the decomposable}

A central tenet of organizational design theory is to group together those tasks that interact with each

other. ${ }^{17}$ Indeed, the desired end state of modularization is to decompose a system into sub-systems that are 
entirely independent of each other or that interact with each other in predictable ways via tightly specified interfaces. ${ }^{18}$ Decisions made in one sub-system then do not affect other sub-systems in unanticipated ways. As a result, no further coordination is necessary and project teams can work in parallel. Such modularity has been touted to lead, for instance, to faster product innovation. ${ }^{19}$ The search for good sets of choices - the equivalent of strategizing in this context - is enhanced by modular organizing.

In light of these potential benefits, a number of U.S. car manufacturers embraced the idea of modular product design. Cars were decomposed into various sub-systems, and cross-functional teams were assigned to each module. To achieve this structure, firms such as Chrysler disbanded their functional organizations in favor of organizing around products and assigning people to temporary project teams. ${ }^{20}$ It is thus somewhat surprising to see that Toyota's vehicle-development process - still the most efficient in the industry - has maintained a functionally based organization, with very limited use of crossfunctional teams. At Toyota, coordination is not achieved (or made less relevant) by a modular design. Rather, high-level chief engineers provide coordination and integration. ${ }^{21}$

How can we explain Toyota's insistence not to organize so that interdependencies are within group boundaries? To shed light onto this question, we consider a decision problem that is perfectly decomposable: the interaction structure shown in Panel B of Figure 3. With this interaction pattern, a task allocation aaaabbbb creates two sub-systems that contain all interactions within the two departments with no interactions across departments. This structure, thus, would correspond to a modular set-up. In contrast, Toyota does not perfectly decompose but uses high-level coordination. This would correspond, for instance, to a task allocation aabbbbaa embedded in a hierarchical structure. In this case, interactions across the two departments (the two functions) still exist, and each department needs to involve the chief engineer (or in our model, the “CEO”) before implementing decisions.

The first two columns in Figure 8 show the average performance in period 200 of firms with these two structures. Surprisingly, even though the decision problem is perfectly decomposable, a task allocation that completely decomposes the decision problem (column 1) does not produce the highest performance. The incompletely decomposed task allocation embedded in a hierarchical structure (column 
2) does better. The performance boost requires both the task allocation aabbbbaa and the hierarchical structure. Adding a chief engineer to the decomposed task allocation aaaabbbb creates no benefit, as a comparison of the first and third columns in Figure 8 shows: once the decision problem is perfectly decomposed and no cross-departmental interdependencies remain, coordination is unnecessary and the extra hierarchical level does nothing (i.e., the first and the third columns show identical performance). Likewise, as the fourth column in Figure 8 shows, adopting a task allocation with overlap but leaving the departments decentralized leads to the worst outcome.

\section{< INSERT FIGURE 8 ABOUT HERE $>$}

Why does an incompletely decomposed task allocation, together with a coordinating level, lead to higher performance than a completely decomposed task allocation? Even when the task allocation places all interactions within departments, each department faces rich interactions internally. That is, it faces a strategizing problem with many local peaks. Each department therefore runs a risk of becoming locked into a suboptimal solution before it explores the range of possibilities broadly. In the firm with the completely decomposed task allocation, each department tends to settle prematurely into a mediocre set of choices. In the firm with incomplete decomposition, interactions across modules create a very different search dynamic: changes in each department alter conditions in the other, prying departments off of equilibria and requiring each department to continue its search. If this firm did not have a coordinator, such conflict between departments could lead to instability and low performance (as seen in the fourth column of Figure 8). With a coordinator, however, who can veto parochially beneficial proposals that undermine total firm performance, the extra search engendered by the interactions that are left in place can lead to superior final results.

It is exactly this dynamic that is portrayed by Sobek, Liker, and Ward in their description of Toyota's product development process. ${ }^{22}$ For instance, in designing a new model of the Celica sports car, the styling department suggested a design change to the front panel, giving the car a more exciting look. This change, however, forced manufacturing to re-think its existing tooling. In response, manufacturing made suggestions, which in turn led to changes in design. The coordination of this exchange was orchestrated at 
the level of the chief engineer and the general manager of manufacturing. From this "conflict” emerged an innovative and easily manufactured design, one that likely would not have arisen without interdependencies across these functions.

This situation gives us the second instance of our general pattern: a good choice of organizing prevents strategizers from locking into sets of choices prematurely, while still allowing the firm to hold onto good solutions. In this case, the "unnecessary” overlap between the departments dislodges each department from early solutions and rejuvenates the search process, while the coordinator makes sure that great sets of choices are not lost. For Section 3's reintegrators, the early period of decentralization ensured broad search, while the later period of integration made good choices permanent.

To show that the underlying mechanism in this section and the last section are very similar, we conduct one last simulation. Rather than using the hierarchical form to create coordination, we construct a decentralized firm that sequences its task allocation from one with overlap (aabbbbaa) to one that perfectly decomposes the system (aaaabbbb). As the fifth column in Figure 8 shows, this sequencing also produces better performance than the perfectly decomposed structure alone can achieve. While the hierarchical structure with overlap creates a simultaneous balance between search and coordination, the sequenced decentralized firm creates this balance over time. In either case, firms that manage this tradeoff well improve performance over a firm that looks, at least at first glance, optimally organized for the decomposable problem it faces.

\section{Low-level exploration that reduces firm-level exploration}

When a firm's environment changes rapidly and radically, top managers often want to encourage the firm to explore a broad range of new possibilities. A common way to do this involves a shift in organizing: give low-level managers wider freedom to consider changes in individual departments, divisions, or regions. This sentiment is expressed most passionately in the popular management literature. When facing an industry inflexion point, says Intel’s Andy Grove, “let chaos reign” for a while before “reining in chaos.” Hamel exhorts top managers to find “activists” and "rebels” far down in the 
organization, while Handy urges firms to place low-level managers in a "federal” structure where "power resides at the lowest possible point." ${ }^{23}$ Unleashed, the low-level managers will explore creative new options and so will the firm.

An implicit assumption in such an organizational shift is that wider exploration at the bottom of a firm will result in broader exploration for the firm as a whole. Conversely, restricting the exploratory efforts of low-level managers will narrow overall exploration. But is this assumption always valid? Case examples cast doubt on it. Consider, for example, an American industrial computing firm that, a few years ago, increased the latitude of department managers to seek innovations. ${ }^{24}$ In response, department managers broadened the array of creative options they considered. Many of the options that department managers brought forward, however, corporate managers felt they had to quash because the proposals did not fit with the direction of the corporation; low-level exploration led to little innovation that was useful to the firm. Subsequently, senior managers forced departments to trim their list of innovative projects by $33 \%$. The rate of new product introductions - a rough proxy for the firm's exploratory success - then rose by $150 \%$. In this last turn of events, restrictions on lower-level exploration appeared, paradoxically, to enhance the exploration of the firm as a whole.

Our simulation sheds light on why lower-level exploration might backfire, narrowing the exploration of the firm as a whole, and why restrictions on lower-level exploration might broaden firm-level exploration. Consider a set of hierarchical firms that face a fully interdependent set of choices, as in Figure 3A. The firms differ from each other in terms of ALT, the number of alternatives to the status quo that each department manager can consider per period. Capturing the degree of lower-level exploration, ALT ranges from 1 (i.e., a department manager can weigh only a single option) to 4 (the manager can explore all four single-decision changes that are possible in the department).

Simulation results, reported in Figure 9, show that average performance declines significantly as department managers engage in greater exploration. The performance decline derives from differences in firm-wide exploration: though all firms face the same performance landscapes, firms with higher ALT explore less of each landscape before locking in on a configuration of choices. For instance, a firm with 
ALT $=1$ adopts about twice as many distinct configurations on average during a 200-period simulation than does a firm with ALT $=4$. Likewise, the average number of sticking points - configurations of choices from which a firm will never change - rises with ALT, as show in Figure 9. These two patterns suggest that, as department-level exploration increases, the firm as a whole gets frozen at more locations and explores less of the landscape. Narrow exploration then causes poor performance. ${ }^{25}$

\section{$<$ INSERT FIGURE 9 ABOUT HERE $>$}

But what's the mechanism by which an increase in departmental exploration narrows exploration for the firm as a whole? The answer lies in the organizational structure of the firm: the incentives, flow of information, and decision allocation within it. Because department managers have a charter to evaluate and sort alternatives before discussing them with the upper-level coordinative body, department managers are able to screen out proposals they do not like and shield them from the view of senior management. The more department managers explore, the more thoroughly they can engage in screening. Consider, for instance, two firms that start with the same configuration of choices: 00001111 (0000 in department A and 1111 in department B). The firms differ only in terms of ALT: ALt = 4 in one firm, and ALT = 1 in the other. Suppose that, among department A's four alternatives, 0001 and 0010 are better than 0000 for the department, and 0100 and 1000 are worse. Finally, recall that department managers are required to send the CEO two proposals each period. In a firm where departmental managers can explore all four alternatives every period $(\mathrm{ALT}=4)$, the manager of department A will always choose 0001 and 0010 as the two proposals to send. The manager will perpetually screen out 0100 and 1000, even if those options are better for the firm as a whole. In a firm with ALT = 1, in contrast, the department manager will pick just one of the four alternatives at random and - required to submit two proposals to the CEO - will send up that alternative regardless of whether he or she likes it. (The manager's other proposal will be the status quo 0000.) In the long run, the department manager can hide nothing from the CEO, and this promotes wide exploration for the firm as a whole.

This simulation result - that greater exploration at the department level dampens exploration for the entire firm - proves to be quite robust. In related work, we have found that the result holds up even when 
department managers have the cognitive power to consider more distant alternatives in their domains, when CEOs can weigh more options per period, when more proposals flow from the departments to the CEO, and when there is less than full interdependence among the firm's decisions. ${ }^{26}$ Only two, extreme changes to the model eliminate the result. First, if there are no interactions at all across the departments, then what is best for the each department is best for the firm as a whole, and the screening out of information does no harm since department managers choose to promote precisely what is in the firm's best interests. Second, screening and its harmful effects disappear if department managers are required to send every alternative they examine to the CEO - an unrealistic situation.

Note that the mechanism at play here is quite similar to the ones in Sections 3 and 4 . In each instance, interactions raise the danger that strategizers will lock-in prematurely and get stuck on low sticking points. Restrictions on low-level search, a period of decentralization, “unnecessary” overlap across departments - all of these are approaches to organizing that encourage adequate exploration in the process of strategizing.

The practical implications of our result become clear through three examples, which illustrate three critical elements of the model. The model posits, first, that managers in one part of a firm may spot an opportunity that is good for the firm as a whole but opt not to communicate it because it is not in their parochial interests. This issue arises often in firms that attempt to cross-sell from one division to another. Andersen Worldwide, for instance, struggled mightily in the 1980s and 1990s to encourage partners in its audit practice to refer leads for consulting engagements to its consulting wing. ${ }^{27}$ Yet the accounting partners, fearful of damaging their reputations with clients and eager to book consulting revenue within the audit division, were reluctant to reveal leads, even when doing so would have been profitable for the firm as a whole. In the words of one industry observer, "most companies have problems cross-selling across their business units... [since the main challenge is] to get one end of the business to help another.,28 In Andersen's case, the struggle ended in an acrimonious corporate divorce.

The second critical element of our model is that high-level managers act to rein in low-level proposals that do not fit corporate objectives. Such high-level discretion is illustrated by events at Whirlpool, the 
world’s largest appliance maker. In 1999, Whirlpool’s Executive Committee sought to encourage “innovation from everywhere and everyone" in order to escape a "stalemate” in its core appliance business. ${ }^{29}$ Regional organizations set up “I-teams” to pursue new opportunities, established "I-boards” to support the I-teams, set up local seed funds for new ideas, and learned innovation techniques from consultants. The resulting burst of pilot projects covered a wide spectrum: a line of exercise equipment, a household maid service, and a modular system of equipment for tailgate parties, for instance. Indeed, many projects were so far removed from Whirlpool’s core business that, by 2001, the Executive Committee had to put new mechanisms in place to rein in the innovations and tie them to existing brands.

Finally, our model requires that low-level exploration, information screening, and high-level oversight combine to produce inertia. As an example, consider Clayton Christensen's description of harddrive manufacturer Seagate’s failure to respond to the then-new 3.5-inch architecture. ${ }^{30}$ While top executives at Seagate received proposals from engineers to support the development of the 3.5-inch product, Seagate's marketing organization sent extensive information to the top executives indicating that the market and the margins for this new product were small. The marketing organization, pursuing its interests, was more eager to develop high-margin products for existing customers and had little incentive to push the new product. Given the alternatives made available by the engineering and marketing departments, top management decided essentially to stick with the technological status quo and to forego broader technological and market exploration. Eventually, this led to a severe decline in Seagate's market position.

These examples suggest four practical responses to the tension we identify, between low-level and firm-level exploration. All four call on a firm to alter how it organizes in order to affect how it strategizes. First, department managers might be given incentives to take firm-level interactions into account when evaluating and proposing alternatives. This mitigates the problem of parochial screening of information, but it dulls incentives at the department level and creates a costly need to provide department managers with the expertise and information to take interactions into account. Andersen, for instance, worked to find incentive-based solutions to its referral problem, but ultimately could not find a system that gave 
both auditors and consultants appropriate incentives to perform well within their own domains and to refer clients to the other part of the business.

Second, a firm might avoid parochial screening by requiring department managers to send up a range of radically different proposals (in our simulation model, more than the two proposals per department), particularly if prior proposals have been rejected. This ensures that a rich variety of ideas reaches the level of the organization at which firm-wide implications can be assessed, and this might pry firms off of lowlying sticking points. Such a requirement, however, increases the coordinating and processing burden on top management. At Whirlpool, for instance, it is hard to imagine getting the desired results from “innovation from everywhere and everyone” by having all 68,000 employees submit proposals, unfiltered, to the nine-person Executive Committee.

Third, top management might define arenas within which low-level managers can explore freely. This makes it less likely that senior managers will subsequently quash departmental initiatives. Whirlpool eventually took this approach, with the CEO identifying the existing brands as the "sandbox" in which regional innovators could "play.” The approach puts some limits on exploration, of course, and it presumes that top managers have the information and insight necessary to spot the promising arenas for strategizing. Moreover, the approach must be taken delicately, lest it suffocate productive sparks of creativity at low levels of a firm. At Whirlpool, for instance, the senior managers who were pulling innovation efforts back into the sandbox had to be very careful to recognize and reward managers who had explored more broadly before the sandbox was defined. This sent a signal that future innovators, within the sandbox, would be rewarded for their contributions.

Lastly, one might radically change the approach to organizing by removing the coordinating body, our CEO. "Decapitation” would eliminate an important source of inertia - the CEO, who retains the status quo rather than engage in any exploration that degrades performance - and this would lead to broader search. But like the decentralized firm in Section 3, such an organization would bear a severe risk of poor coordination between department managers. In sum, we see several practical responses that may mitigate the tension between low-level exploration and firm-level exploration, but none that costlessly resolves it. 


\section{Discussion and conclusion}

Decades of research on organizations have produced a rich variety of valuable perspectives on the role of organizing. Organizational design decisions have been viewed in light of their impact on a firm's ability to process information, their effect on the motivation of employees to expend effort, and their

influence on firm incentives to invest in relationship-specific assets, for instance. ${ }^{31}$ The lens we adopt highlights the impact of organizing on strategizing. Organizing affects how a management team searches for a set of intertwined choices that enables a firm to thrive in its environment - that is, how the team strategizes. In emphasizing the effect of organizing on strategizing and stressing the role of interactions, we echo classic research on organizations: Alfred Chandler on structures that enable strategies involving massive coordination of goods; Paul Lawrence and Jay Lorsch on organizations that integrate differentiated parts; and James Thompson on organizations that handle pooled, sequential, and reciprocal interdependence among tasks. ${ }^{32}$ Our claim is not that organizing matters only because it affects strategizing. Rather, our view is that one major role of organizing is to set the stage for strategizing. We feel that recent research has paid too little attention to this role and, in particular, to the way that interactions affect this role.

Interactions among decisions make strategizing difficult. They raise the specter that incremental search for a good set of choices will leave a firm prematurely stuck - saddled with poor performance, yet lacking a clear path for improvement. A role of organizing is to help managers cope with this challenge. Good organizational structures help a firm achieve two ends that may seem at odds with each other: to search broadly for a good combination of strategic choices, and to lock in on such a combination once it is discovered. The seemingly odd features of our main examples - the period of decentralization at Schwab, the unnecessary overlap across departments at Toyota, and the reining in of low-level managers at the industrial computing company - all were mechanisms to encourage broad search. Each served to shake strategizing efforts off low sticking points and guide them toward higher optima. Each prevented a firm from locking into a sticking point prematurely, before a wide range of options was considered. And each was coupled with an organizational device to achieve stability in the long run: a period of integration at 
Schwab, and a central coordinator at Toyota and the industrial computing company. In the face of interactions, a central challenge of organizing efforts is to balance search and stability.

The model that produces this insight has certain limits. Perhaps most strikingly, it focuses exclusively on formal aspects of organizational design such as the vertical hierarchy and the allocation of tasks to department managers. It ignores informal aspects of design such as corporate culture and social networks, which surely play important roles in achieving coordination in real firms. Informal design elements are an intriguing subject for future research. Even though the model in this paper ignores informal aspects of design, the model illustrates two general ways in which agent-based simulations of organizational design are useful. First, the model offers a tool for exploring design choices that are seemingly odd yet effective. Second, such simulations enable us to drill down to fundamental considerations that drive design in the face of interactions - for instance, the need to balance search and stability.

The onus for striking this balance falls on senior management. More broadly, senior managers bear responsibility for dealing with interactions among decisions, particularly interactions that span department borders. In a sense, it is such interactions that make senior management necessary: without cross-cutting interactions, department managers could make decisions independently and the firm would be no worse for it. Our perspective is that effective senior managers usually cope with intricate interactions not by "figuring it all out” and enacting the perfect strategy up-front, but by crafting an organization that can search effectively for and stabilize around a great strategy. The shift in mindset from "my job is to design a great strategy" to "my job is to design an organization that can search well for a great strategy" is challenging but crucial.

The need to balance search and stability has an intriguing implication. It is widely acknowledged that firms ossify as they age. In the popular business press, this tendency is bemoaned, and dinosaurs are urged to dance. Among scholars, the presence of inertia is more willingly accepted. In particular, Michael Hannan and John Freeman have argued that customers and other constituencies want organizations to be reliable and accountable, and these traits may require some structural inertia. ${ }^{33}$ Thus there are reasons 
that, in ecological competition, inert firms may be selected for survival. While this logic identifies some benefits of inertia once it arrives, it does not explain why the gradual onset of inertia may be beneficial.

Our models and our examples identify, however, a virtue of creeping ossification - gradual movement from ways of organizing that encourage broad search toward ways of organizing that embrace stability. In the face of interactions, a firm that is stable from the outset will lock in on a sticking point quickly, even if the sticking point produces mediocre performance. A firm that never stabilizes will wander broadly, again achieving mediocre performance on average (despite fleeting moments of brilliance). A happy medium resides in a firm that shifts over time from broad search toward stability. Early on, it embraces temporary downward movement on the performance landscape, accepting this as the cost of broad search. Over time, it becomes less accepting of downward movement until it locks in permanently on a way of doing business. This process resembles “annealing,” a well-known mathematical technique for solving tough combinatorial optimization problems. ${ }^{34}$ In this logic, we see an argument, albeit a speculative one, that firms may benefit from the gradual onset of inertia, not just the presence of inertia. The key to successful strategizing may lie in organizing to manage the transition from search to stability, and back to search should an environmental change require renewed adaptation. Competition may select for survival those firms that organize well to strategize. 
Figure 1: Performance landscape with no interactions

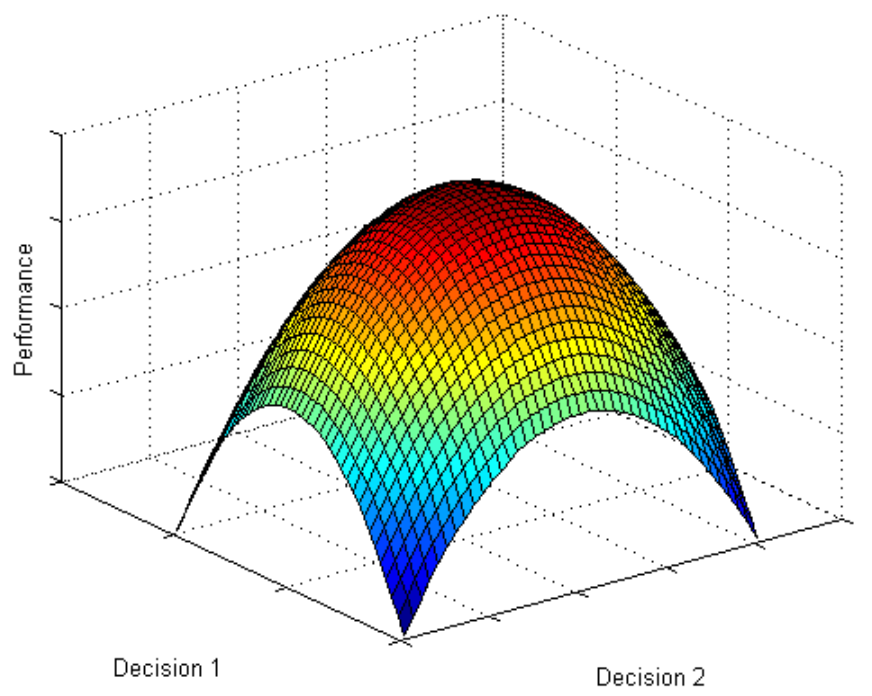

Figure 2: Performance Landscape with interactions

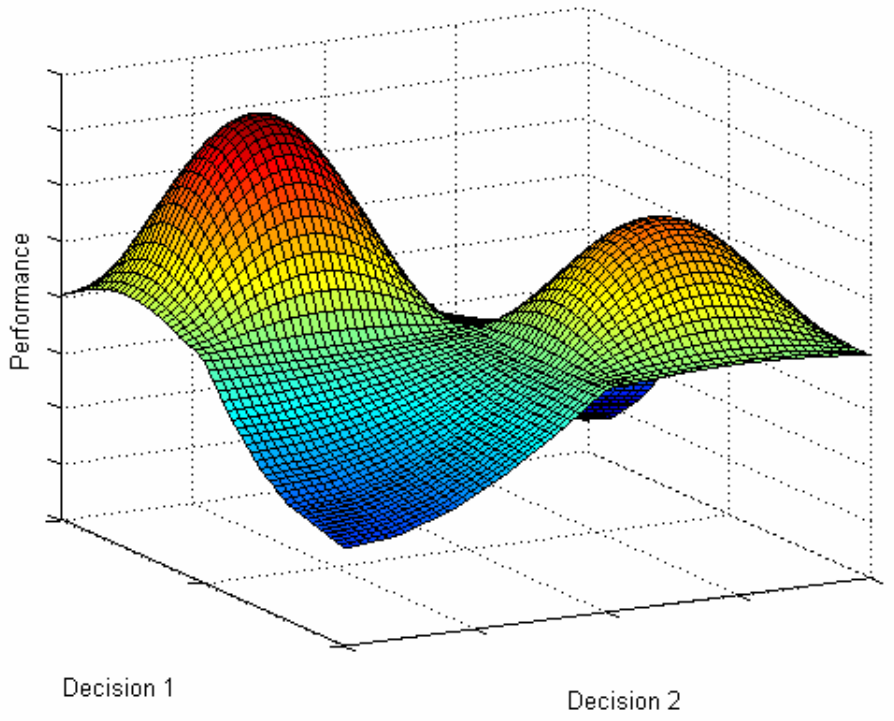


Figure 3: Influence matrices

A. Fully interdependent influence matrix

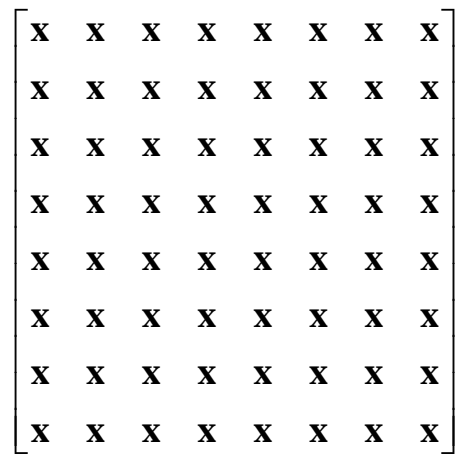

Figure 4: Different organizational structures

\section{Decentralized structure}

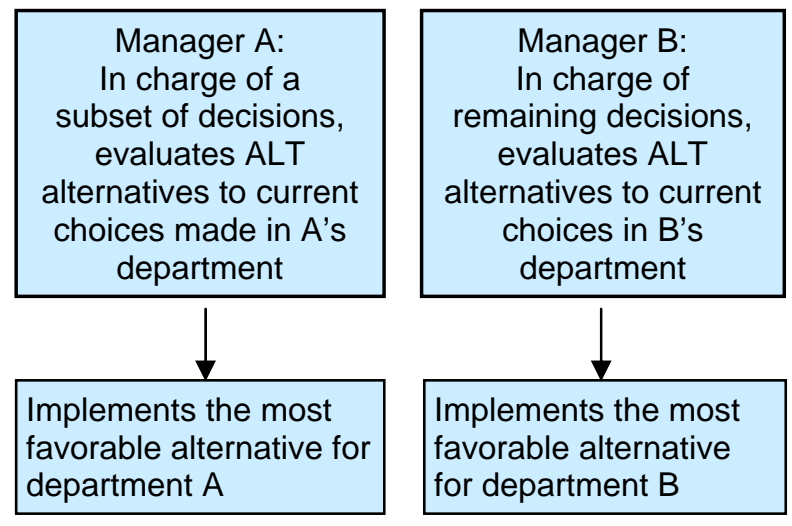

Manager A:

charge of ubset of decisions

alternatives to current

s made in A's partment
Manager B: aining decisions, rnatives to current hoices in B's
B. Modular influence matrix

$$
\left[\begin{array}{llllllll}
\mathbf{x} & \mathbf{x} & \mathbf{x} & \mathbf{x} & & & & \\
\mathbf{x} & \mathbf{x} & \mathbf{x} & \mathbf{x} & & & & \\
\mathbf{x} & \mathbf{x} & \mathbf{x} & \mathbf{x} & & & & \\
\mathbf{x} & \mathbf{x} & \mathbf{x} & \mathbf{x} & & & & \\
& & & & \mathbf{x} & \mathbf{x} & \mathbf{x} & \mathbf{x} \\
& & & & \mathbf{x} & \mathbf{x} & \mathbf{x} & \mathbf{x} \\
& & & & \mathbf{x} & \mathbf{x} & \mathbf{x} & \mathbf{x} \\
& & & & \mathbf{x} & \mathbf{x} & \mathbf{x} & \mathbf{x}
\end{array}\right]
$$

Hierarchical structure

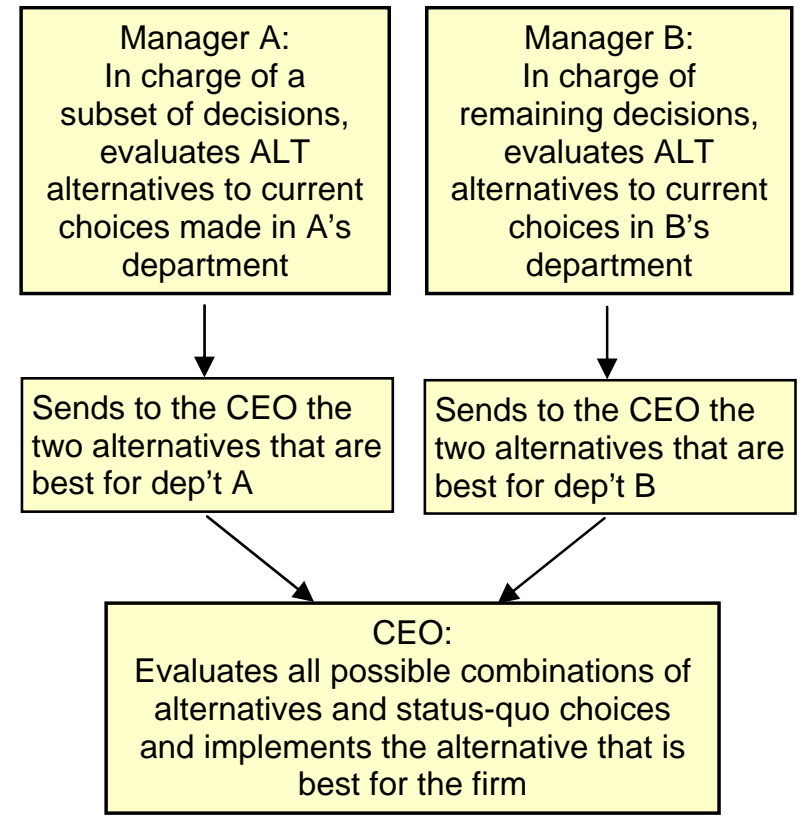


Figure 5: The benefits of reintegration in the presence of interactions

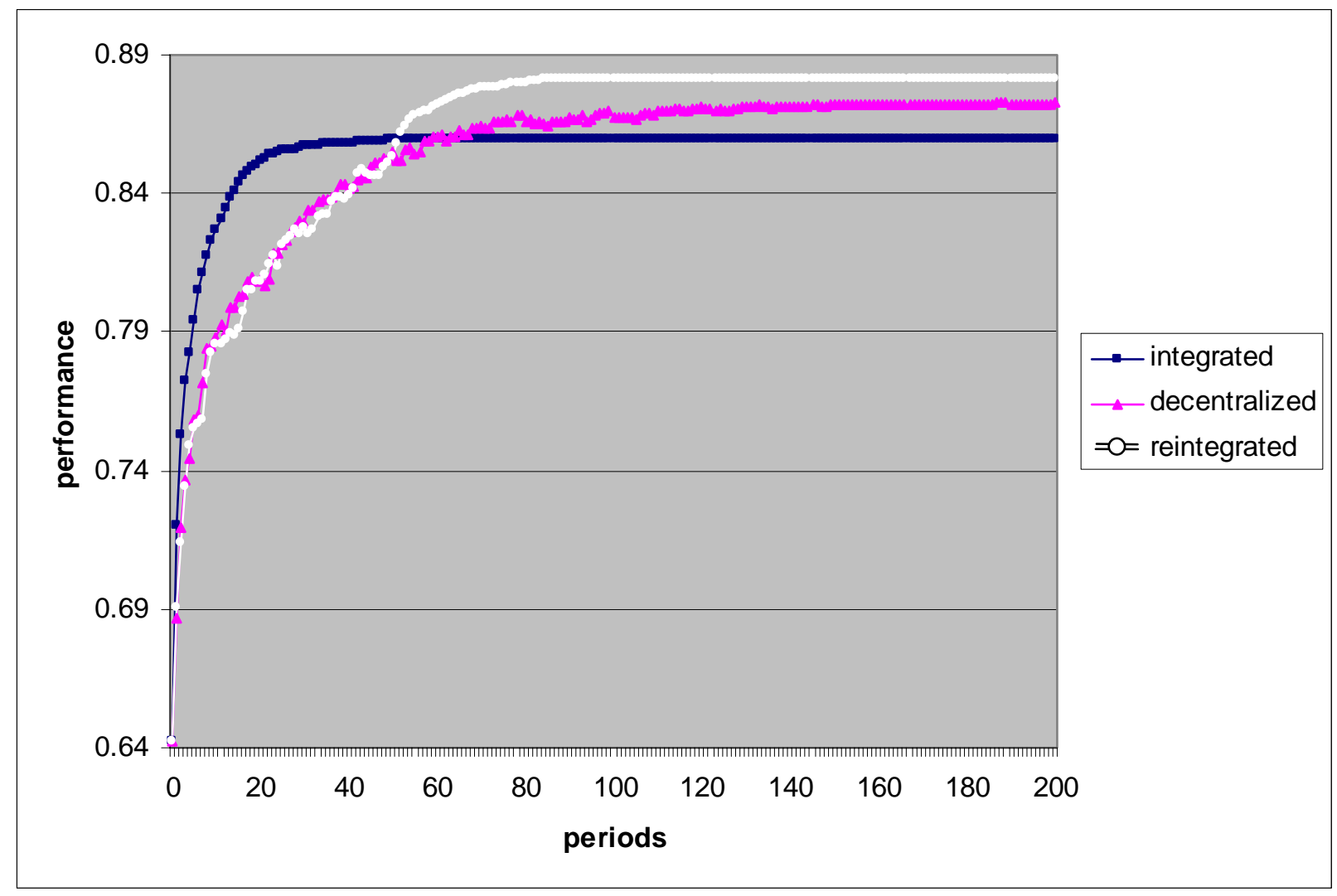


Figure 6: Reintegration does not yield a benefit in the absence of interactions

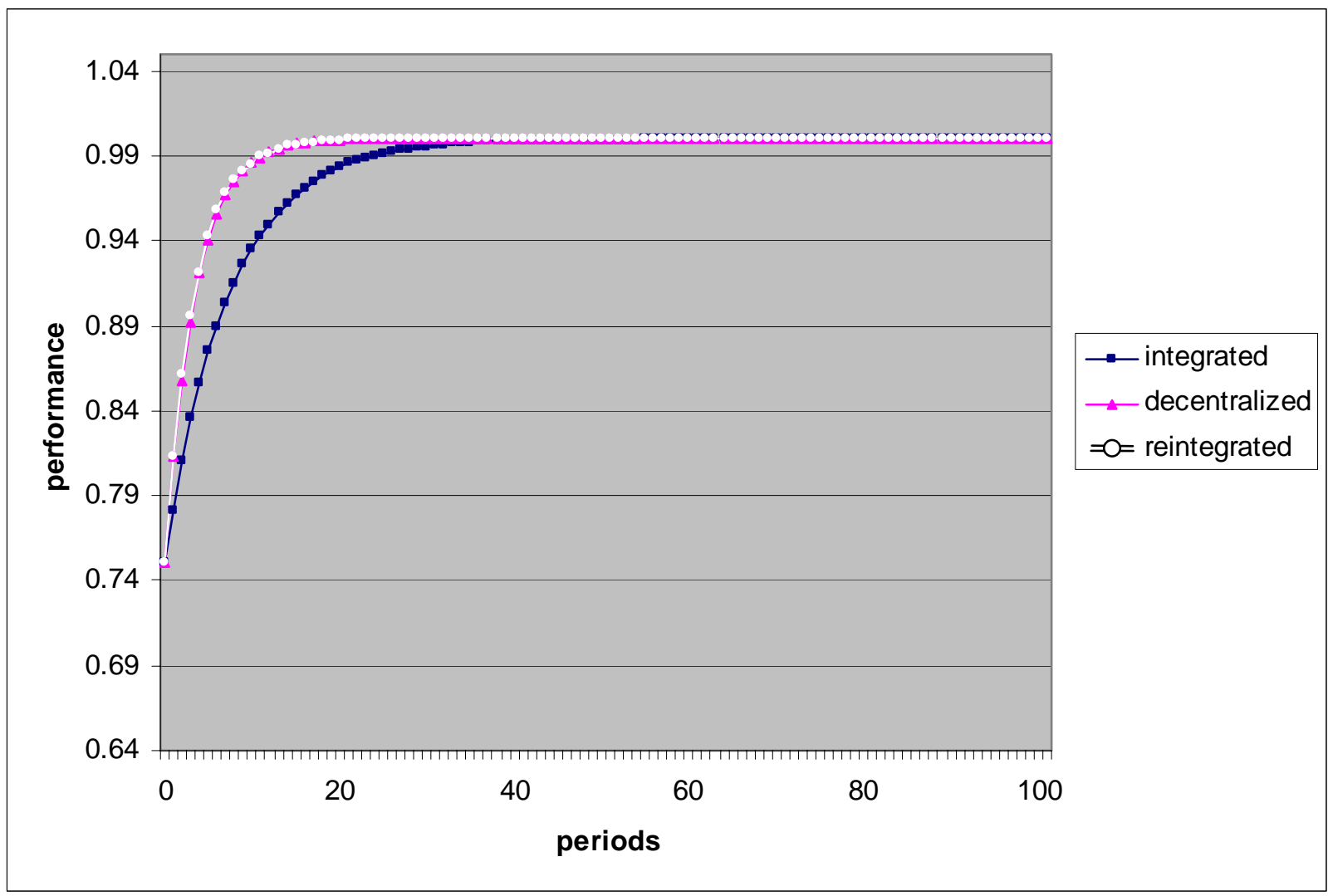


Figure 7: The benefit of reintegration as a function of the degree of environmental change

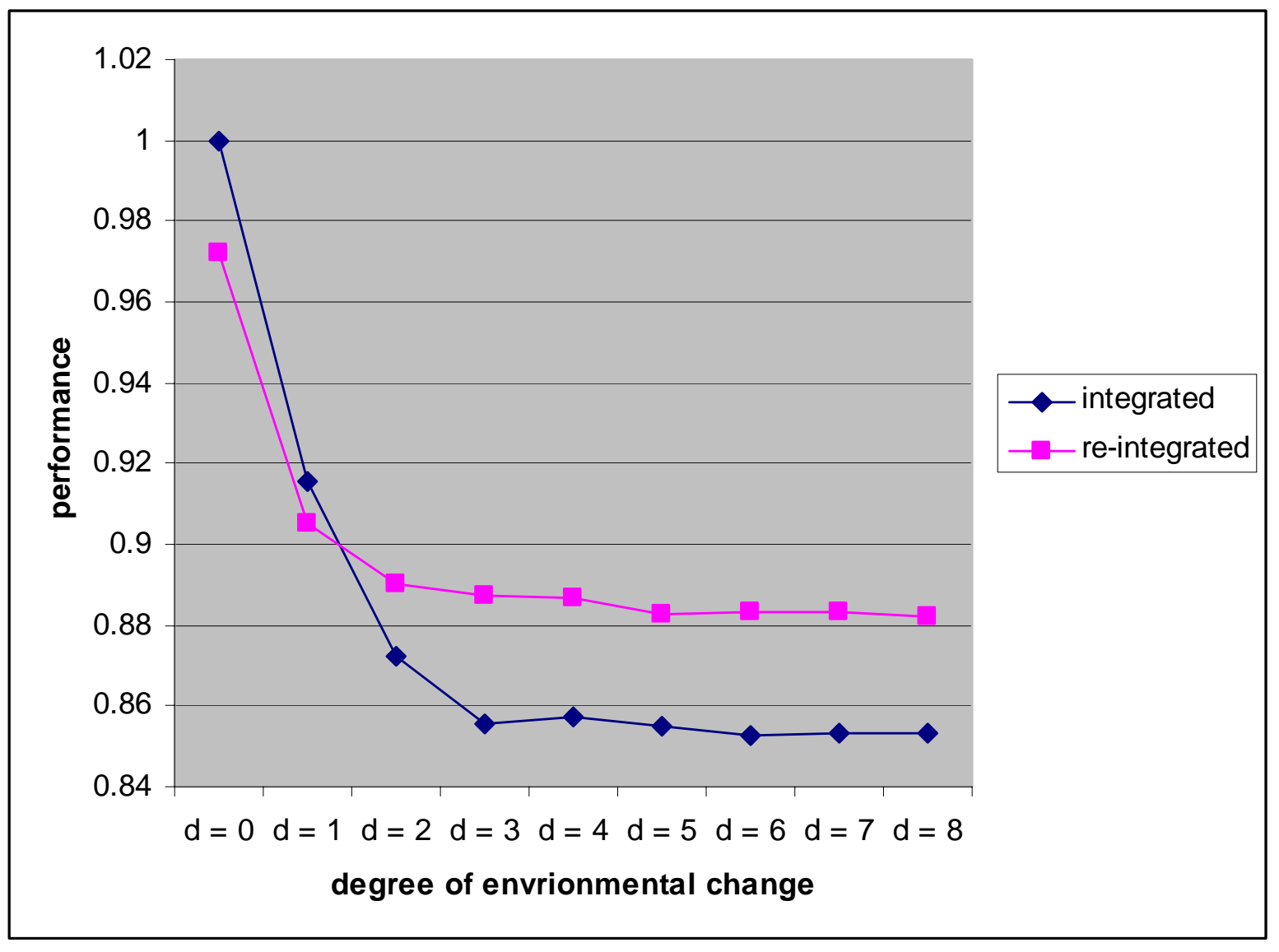


Figure 8: The benefits of unnecessary overlap

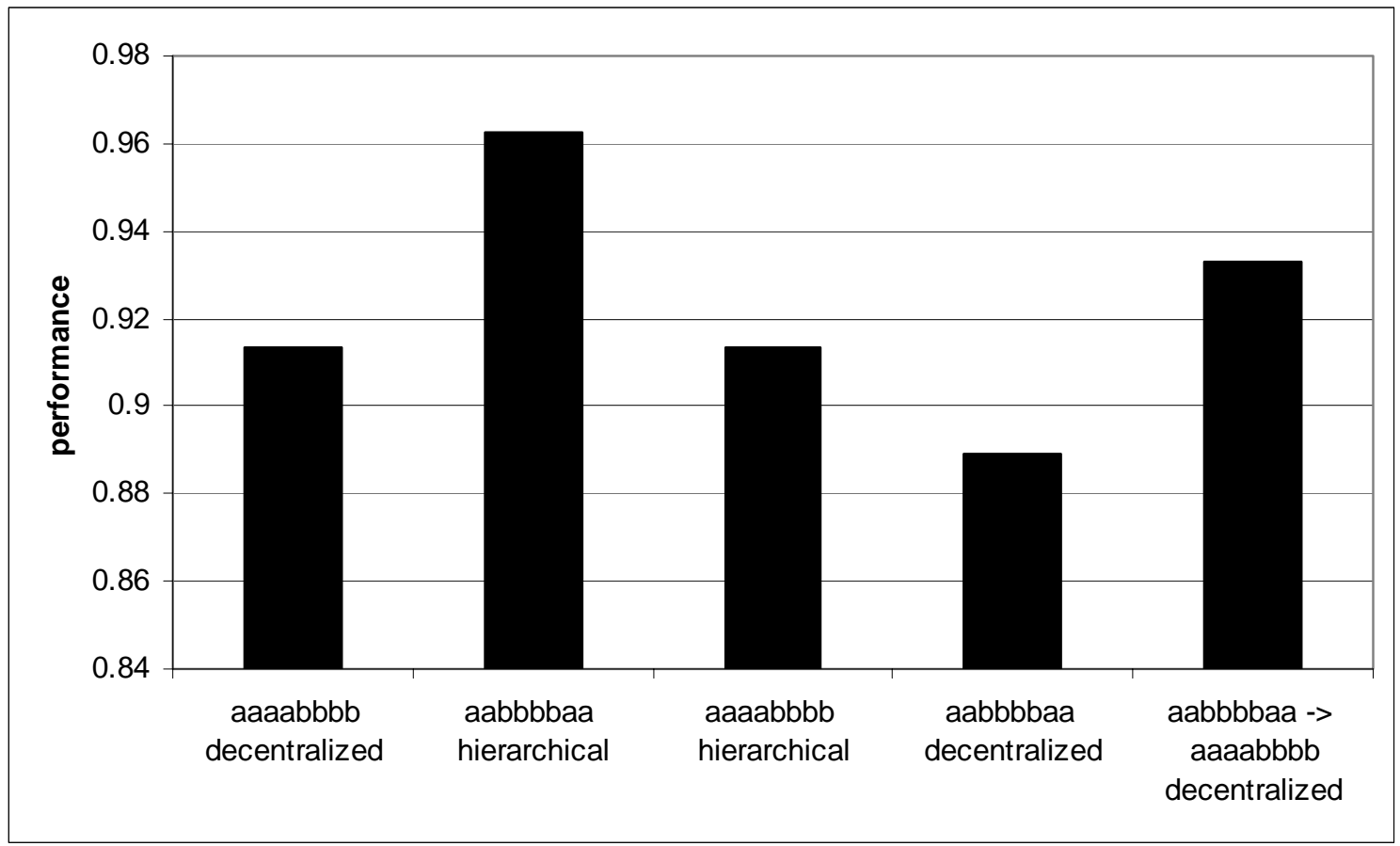

Figure 9: The potential pitfall of lower level exploration

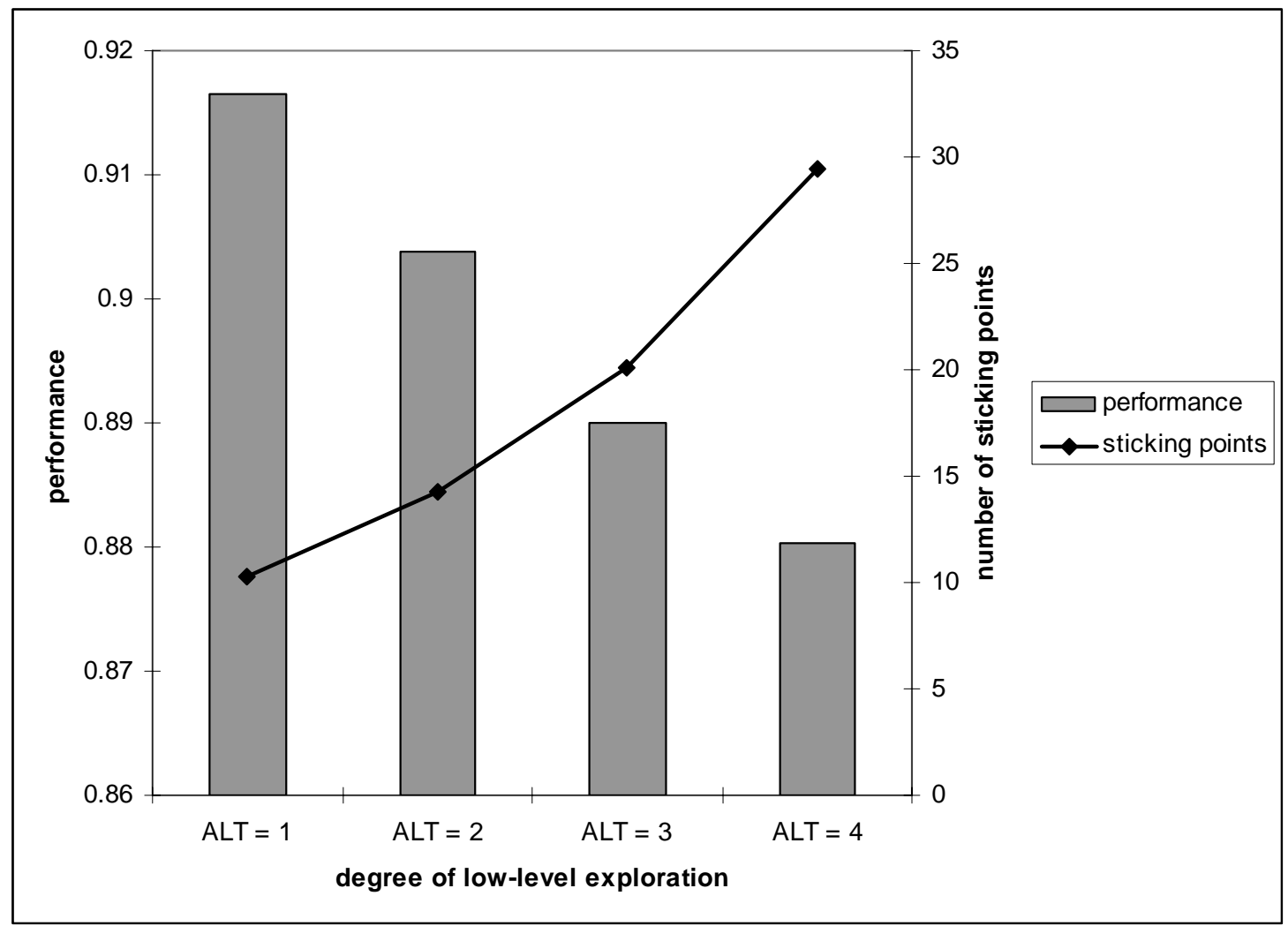




\section{References}

${ }^{1}$ T. Burns and G. M. Stalker. The Management of Innovation, Tavistock, London (1961); P. R. Lawrence and J. W. Lorsch. Organization and Environment, Harvard Business School Press, Boston (1967).

2 J. L. Bower. Managing the Resource Allocation Process, Harvard Business School Press, Boston (1970); D. J. Hall and M. A. Saias, Strategy follows structure!, Strategic Management Journal 1: 149-163 (1980); R. P. Rumelt. Strategy, Structure, and Economic Performance, Division of Research, Graduate School of Business Administration, Harvard University, Boston (1974); H. Mintzberg. The Structuring of Organizations, Prentice Hall, Englewood Cliffs, NJ (1979).

${ }^{3}$ In this paper, we focus on the way that organizing influences strategizing. Some research, in contrast, emphasizes how strategizing affects organizing. In his seminal history of American enterprise, Chandler not only introduced the distinction between organizing and strategizing, but he also argued forcefully that a strategy of product-market diversification required a divisionalized organizational structure. (A. D. Chandler, Jr. Strategy and Structure: Chapters in the History of Industrial Enterprise, MIT Press, Cambridge, MA (1962)) His dictum that "strategy follows structure" highlighted the impact of strategizing on organizing. Subsequent research has confirmed the mutual dependence of strategizing and organizing: "structure follows strategy as the left foot follows the right in walking.... None takes precedence; each always precedes the other, and follows it...” (H. Mintzberg, The design school: Reconsidering the basic premises of strategic management, Strategic Management Journal 11: 171-195 (1990), p. 183). Empirical evidence has supported the notion that the two are reciprocally dependent (e.g., T. L. Amburgey and T. Dacin, As the left foot follows the right? The dynamics of strategic and structural change, Academy of Management Journal 37: 1427-1452 (1994)).

${ }^{4}$ Indeed, in 1915, one of the earliest precursors to modern strategy courses, Harvard's Business Policy course, devoted half of its course description to interdependencies: "An analysis of any business problem shows not only its relation to other problems in the same group, but also the intimate connection of groups. For example, not only is any problem of factory management related to other problems in the factory, and any problem of selling related to other problems in the sales department, but also the groups of problems are interdependent. Few problems in business are purely intra-departmental" (Harvard University. Official Register of Harvard University, Graduate School of Business Administration, Cambridge, MA (1917), p. 36). In recent years, theoretical work on supermodular systems (P. R. Milgrom and J. Roberts, The economics of modern manufacturing: Technology, strategy, and organization, American Economic Review 80: 511-528 (1990)), empirical studies of industries and individual firms (C. Ichniowski, K. Shaw and G. Prennushi, The effects of human resource management practices on productivity: A study of steel finishing lines, American Economic Review 87: 291-313 (1997); R. Whittington, A. Pettigrew, S. Peck, E. Fenton and M. Conyon, Change and complementarities in the new competitive landscape: A European panel study, 1992-1996, Organization Science 10: 583-600 (1999); N. Siggelkow, Evolution toward fit, Administrative Science Quarterly 47: 125-159 (2002); A. M. Pettigrew, R. Whittington, L. Melin, C. SanchezRunde, F. A. J. Van den Bosch, W. Ruigrok and T. Numagami, Eds. Innovative Forms of Organizing, Sage, London (2003)), prescriptive articles for managers (M. E. Porter, What is strategy?, Harvard Business Review 74(6): 61-78 (1996)), and simulation studies of firms as complex adaptive systems (D. A. Levinthal, Adaptation on rugged landscapes, Management Science 43: 934-950 (1997); J. W. Rivkin and N. Siggelkow, Balancing search and stability: Interdependencies among elements of organizational design, Management Science 49: 290-311 (2003)) have reflected a renewed interest in the interactions among decisions.

${ }^{5}$ See for instance, P. N. Khandwalla. The Design of Organizations, Harcourt Brace Jovanovich, New York (1977).

${ }^{6}$ S. A. Kauffman. The Origins of Order: Self-Organization and Selection in Evolution, Oxford University Press, New York (1993); D. A. Levinthal, Adaptation on rugged landscapes, Management Science 43: 934-950 (1997).

${ }^{7}$ H. A. Simon. Models of Man: Social and Rational; Mathematical Essays on Rational Human Behavior in a Social Setting, John Wiley, New York (1957). 
${ }^{8}$ See, for instance, R.M. Cyert and J. G. March, A Behavioral Theory of the Firm, Prentice Hall, Englewood Cliffs, NJ (1963); M.D. Cohen, J. G. March, and J. P. Olsen, A garbage can model of organizational choice, Administrative Science Quarterly 17 1-25 (1972); and R.M. Burton and B. Obel, Designing Efficient Organizations: Modelling and Experimentation, North-Holland, Amsterdam (1984).

${ }^{9}$ In particular, the reader may refer to the following papers in which various results presented in this paper have been discussed in detail: J. W. Rivkin and N. Siggelkow, Balancing search and stability: Interdependencies among elements of organizational design, Management Science 49: 290-311 (2003); N. Siggelkow and D. Levinthal, Temporarily divide to conquer: Centralized, decentralized, and reintegrated organizational approaches to exploration and adaptation, Organization Science 14: 650-669 (2003); N. Siggelkow and J. W. Rivkin, Speed and search: Designing organizations for turbulence and complexity, Organization Science 16: 101-122 (2005); N. Siggelkow and D. A. Levinthal, Escaping real (non-benign) competency traps: Linking the dynamics of organizational structure to the dynamics of search, Strategic Organization 3: 85-115 (2005); N. Siggelkow and J. W. Rivkin, When exploration backfires: Unintended consequences of multi-level organizational search, working paper, Wharton School of Business, Philadelphia (2005).

${ }^{10} \mathrm{~J}$. H. Dyer and W. Hesterly, Winning the web wars: A blueprint for advantage in the online marketspace, working paper, Brigham Young University and University of Utah, (2000).

${ }^{11}$ Ibid.

${ }^{12}$ J. W. Rivkin and N. Siggelkow, Organizational sticking points on NK-landscapes, Complexity 7(5): 31-43 (2002).

${ }^{13}$ D. Levinthal and J. March, A model of adaptive organizational search, Journal of Economic Behavior and Organizations 2: 307-333 (1981); B. Levitt and J. G. March, Organizational learning, Annual Review of Sociology 14: 319-340 (1988).

${ }^{14}$ M. L. Tushman and P. Anderson, Technological discontinuities and organizational environments, Administrative Science Quarterly 31: 439-465 (1986).

${ }^{15}$ For a broader range of structures, see N. Siggelkow and J. W. Rivkin, Speed and search: Designing organizations for turbulence and complexity, Organization Science 16: 101-122 (2005); N. Siggelkow and D. A. Levinthal, Escaping real (non-benign) competency traps: Linking the dynamics of organizational structure to the dynamics of search, Strategic Organization 3: 85-115 (2005).

${ }^{16}$ On average, this rejuvenation tends to be beneficial. Call a firm's current organizational structure A, and the new structure B. Each structure generates a set of sticking points. Some sticking points are unique to each structure; some are sticking points for both structures. Joint sticking points tend to have much higher performance than unique sticking points (because these are configurations that are seen as non-improvable by two structures rather than only by one). When a firm changes from $\mathrm{A}$ to $\mathrm{B}$, it gets dislodged from the low, unique sticking points but not from the higher-performing joint sticking points. Many of the dislodged firms will end up on the high joint sticking points and the remaining on the unique sticking points of $\mathrm{B}$. On average, then, performance increases due to the organizational change.

${ }^{17}$ See for instance, J. D. Thompson. Organizations in Action, McGraw-Hill, New York (1967); J. R. Galbraith. Designing Complex Organizations, Addison-Wesley, Reading, MA (1973).

${ }^{18}$ C. Y. Baldwin and K. B. Clark. Design Rules: The Power of Modularity, MIT Press, Cambridge (2000).

${ }^{19}$ R. Sanchez and J. T. Mahoney, Modularity, flexibility, and knowledge management in product and organization design, Strategic Management Journal 17(winter special issue): 63-76 (1996).

${ }^{20}$ D. K. Sobek, J. K. Liker and A. C. Ward, Another look at how Toyota integrates product development, Harvard Business Review 76(July-August): 36-49 (1998). 
21 Ibid.

${ }^{22}$ Ibid.

${ }^{23}$ A. S. Grove. Only the Paranoid Survive, Doubleday, New York (1996); G. Hamel. Leading the Revolution, Harvard Business School Press, Boston (2000); C. Handy, Balancing corporate power: A new Federalist paper, Harvard Business Review 70(6): 59-67 (1992).

${ }^{24}$ We are grateful to Nitin Nohria for this example. The identity of the corporation has been kept in confidence.

${ }^{25}$ While the relationship between ALT and the number of sticking points is monotonic, the relationship between ALT and performance need not always be monotonic. There can exist an intermediate level of ALT at which performance is maximized, since higher levels of ALT increase the degree to which good opportunities are utilized. Performance, however, always declines as ALT reaches very high levels. For additional details, see N. Siggelkow and J. W.

Rivkin, When exploration backfires: Unintended consequences of multi-level organizational search, working paper, Wharton School of Business, Philadelphia (2005).

${ }^{26}$ N. Siggelkow and J. W. Rivkin, When exploration backfires: Unintended consequences of multi-level organizational search, working paper, Wharton School of Business, Philadelphia (2005).

${ }^{27}$ A. Nanda, Family feud (A): Andersen vs. Andersen, Harvard Business School Case 800-064, (1999).

${ }^{28}$ P. Carty, Adding value proves taxing, The Independent(February 15): 27 (1995).

${ }^{29}$ J. W. Rivkin, D. Leonard and G. Hamel, Change at Whirlpool Corporation (A), (B), and (C), Harvard Business School Cases 705-462, 705-463, and 705-464, (2005).

${ }^{30}$ C. M. Christensen. The Innovator's Dilemma, Harvard Business School Press, Boston (1997).

31 J. R. Galbraith. Designing Complex Organizations, Addison-Wesley, Reading, MA (1973); M. C. Jensen and W. $\mathrm{H}$. Meckling, Theory of the firm: Managerial behavior, agency costs and ownership structure, Journal of Financial Economics 3: 305-360 (1976); O. E. Williamson. Markets and Hierarchies, Free Press, New York (1975); S. J. Grossman and O. D. Hart, The costs and benefits of ownership: A theory of vertical and lateral integration, Journal of Political Economy 94: 691-719 (1986).

${ }^{32}$ A. D. Chandler, Jr. Strategy and Structure: Chapters in the History of Industrial Enterprise, MIT Press, Cambridge, MA (1962); P. R. Lawrence and J. W. Lorsch. Organization and Environment, Harvard Business School Press, Boston (1967); J. D. Thompson. Organizations in Action, McGraw-Hill, New York (1967).

${ }^{33}$ M. T. Hannan and J. Freeman, Structural inertia and organizational change, American Sociological Review 49: 149-164 (1984)

${ }^{34}$ S. Kirkpatrick, C. D. Gelatt, Jr. and M. P. Vecchi, Optimization by simulated annealing, Science 220: 671-680 (1983) 